\title{
Risk factors associated with driving after cannabis use among Canadian young adults
}

Running title: Factors associated with driving after cannabis use

Christophe Huỳnh, Ph.D. (1-3), Alexis Beaulieu-Thibodeau, B.Sc. (1,4), Jean-Sébastien Fallu, Ph.D. $(1,2,5)$, Jacques Bergeron, Ph.D. (1,4), Jorge Flores-Aranda, Ph.D. (1,6), Alain Jacques, M.Sc. (7), Serge Brochu, Ph.D. $(1,8)$

1. University Institute on Addictions, CIUSSS Centre-Sud-de-l'Île-de-Montréal, Montréal (Québec), Canada

2. School of Psychoeducation, Université de Montreal, Montréal (Québec), Canada

3. Department of Psychiatry and Addiction, Université de Montréal (Québec), Canada

4. Department of Psychology, Université de Montréal, Montréal (Québec), Canada

5. Centre for Public Health Research, Université de Montréal and CIUSSS Centre-Sud-del'Île-de-Montréal, Montréal (Québec), Canada

6. School of Social Work, Université du Québec à Montréal, Montréal (Québec), Canada

7. Program to Assess and Reduce the Risk of Impaired Driving, CIUSSS Centre-Sud-de-l'Îlede-Montréal, Montréal (Québec), Canada

8. School of Criminology, Université de Montréal, Montréal (Québec), Canada

Corresponding author:

Christophe Huỳnh, Ph.D.

University Institute on Addictions

Centre intégré universitaire de santé et des services sociaux du Centre-Sud-de-l'Île-de-Montréal 950 rue de Louvain Est, Montreal (Quebec) H2M 2E8 Canada

Phone: (514) 385-1232 ext. 2302

Email: christophe.huynh.ccsmtl@ssss.gouv.qc.ca

Published in Journal of Drug Issues (October 11, 2021) :

https://doi.org/10.1177/00220426211049359 


\begin{abstract}
This study identifid the most prominent risk factors associated with driving after cannabis use (DACU). 1,126 Canadian drivers (17-35 years old) who have used cannabis in the past 12 months completed an online questionnaire about sociodemographic information, substance use habits, cannabis effect expectancies, driving behaviours and peers' behaviours and attitudes concerning DACU. A hierarchical logistic regression allowed identifying variables that were associated with DACU. Income (CA $\$ 30,000-C A \$ 69,000)$, weekly-to-daily cannabis use, higher level of cannabis-related problems, expectation that cannabis facilitates social interactions, drunk driving, belief that DACU is safe, general risky driving behaviours, having a few friends who had DACU and injunctive norms predicted past 12-month DACU. Older age, holding negative expectations concerning cannabis, driving aggressively and perceived accessibility of public transportation decreased the probability of DACU. With restricted resources, programmes will be more efficient by targeting Canadian young adults most inclined to DACU by focusing on these risk factors.
\end{abstract}

Keywords: cannabis, driving under the influence, automobile driving, risk factors, risk-taking, Canada 


\section{INTRODUCTION}

DACU (driving after cannabis use) is not uncommon in Canada. According to self-reported surveys, before cannabis legalization, 39\% of Canadian cannabis users declared driving within 2 hours after using cannabis in the past 12 months (Health Canada, 2019). After cannabis legalization, this rate dropped to $26 \%$ in 2019 and to $22 \%$ in 2020 (Health Canada, 2020). Previous studies have highlighted that recent cannabis use decreases the cognitive and psychomotor abilities required for driving such as reaction time, motor coordination, time perception, concentration, short-term memory and shared attention (Bondallaz et al., 2016; Capler, Bilsker, Van Pelt, \& MacPherson, 2017; Doroudgar et al., 2018; Hartman \& Huestis, 2013; Mikulskaya \& Martin, 2018a; 2018b; Rogeberg \& Elvik, 2016). Regardless of age, sex and history of misconduct, the presence of THC (delta-9-tetrahydrocannabinol), the main psychoactive molecule in cannabis, in the blood was associated with a greater likelihood of collisions (Asbridge, Hayden, \& Cartwright, 2012; Bédard, Dubois, \& Weaver, 2007). Between 2003 and 2013, administrative databases concerning motor vehicle collisions in Ontario show that $5.1 \%$ of collisions involved a driver who tested positive for THC in the blood (Bédard et al., 2007). In 2012, it was estimated that 75 Canadians died in a road accident involving cannabis and 4,407 were physically injured, representing CA $\$ 1.09$ billion in financial costs (Wettlaufer et al., 2017).

Previous studies have identified different sets of risk factors associated with DACU. Concerning sociodemographic characteristics, DACU is more common among individuals under 35 years old (Domingo-Salvany et al., 2017; Voas, Lacey, Jones, Scherer, \& Compton, 2013). Recent cannabis users aged 18-24 constitute the age group who is the most 'open' to the idea of DACU (Davis et al., 2016). Although some studies report a higher proportion of males being implicated in DACU (Arterberry et al., 2013; Voas et al., 2013), others do not find an association 
between being male and DACU (Aston, Merrill, McCarthy, \& Metrik, 2016; Domingo-Salvany et al., 2017). There were no discernible patterns in methodology (i.e. DACU definition operationalization, sample characteristics, variables included in regression models) to explain this divergence. While Davis et al. (2016) found that American adults in the general population with a lesser level of education or who had a job had a higher probability of DACU, these findings were not reported in specific samples such as high school students (Minaker et al., 2017; O'Malley \& Johnston, 2013; Wilson et al., 2018) or adults who drive on weekend evenings (Voas et al., 2013). Characteristics related to cannabis use are associated with an increased likelihood of DACU, such as frequency (Arterberry et al., 2013; Arterberry, Treloar, \& McCarthy, 2017; Berg et al., 2018; Borodovsky et al., 2020; Cuttler, Sexton, \& Mischley, 2018; Matthews, Bruno, Dietze, Butler, \& Burns, 2014; Sukhawathanakul, Thompson, Brubacher, \& Leadbeater, 2019; Whitehill, Rodriguez-Monguio, Doucette, \& Flom, 2019), greater quantity consumed within a given time frame (Cuttler et al., 2018; Davis et al., 2016; Le Strat, Dubertret, \& Le Foll, 2015) and presence of cannabis-related problems or disorders (Choi, DiNitto, \& Marti, 2019; Cook, Shank, Bruno, Turner, \& Mann, 2017; Le Strat et al., 2015; Scherer, Voas, \& Furr-Holden, 2013). While some studies suggest that alcohol users holding positive expectations regarding drinking are more likely to be driving under the influence of alcohol, the relationship is less clear between expectations of cannabis effects among cannabis users and DACU. Notably, the three previous studies on this specific association report divergent results, probably due to differences in sample characteristics (i.e. regarding cannabis use frequency and age grouping). As such, Arterberry et al. (2013) found that negative expectations of cannabis effects were associated with a decreased likelihood of DACU among college students who had used cannabis at least once in their lifetime, while Ewing et al. (2015) reported that holding previously positive expectations concerning cannabis at ages 12 
and 14 increased the likelihood of subsequent DACU among 16-year-old adolescents. Only 3.1\% of the 12-year-old sample participants had used cannabis in the previous month; this rate increased to $9.8 \%$ at 14 years old. According to another study conducted by Aston et al. (2016), neither positive nor negative expectations regarding cannabis effects were associated with DACU among 18- to 30-year-old frequent cannabis users (ranging from at least once per week in the past month to at least 10 times in the past 6 months).

Individuals who engage in DACU are also more likely to present other risky road behaviours (Bergeron \& Paquette, 2014). These include heavy drinking, drunk driving and dangerous driving such as speeding or being erratic on the road (Bédard et al., 2007; Bingham, Shope, \& Zhu, 2008). Another explanation for DACU is that individuals do not have other alternative transportation. Providing appropriate, affordable and viable alternative transportation is a way to prevent driving after alcohol or drug use in general (Duff \& Rowland, 2006), but it is less known if this also applies specifically for cannabis. Additionally, individuals who engage in DACU may not perceive this behaviour as risky, considering that some declare that they do not believe cannabis impairs driving (Berg et al., 2018; Cuttler et al., 2018; Danton, Misselke, Bacon, \& Done, 2003; Greene, 2018; Kohn, Saleheen, Borrup, Rogers, \& Lapidus, 2014; Terry \& Wright, 2005; Wickens, Watson, Mann, \& Brands, 2019). Some even report that cannabis improves their abilities by promoting a state of relaxation (Danton et al., 2003; Wickens et al., 2019) and that they compensate for cognitive and psychomotor deficiencies caused by cannabis (Fischer, Rodopoulos, Rehm, \& Ivsins, 2006; Greene, 2018). Also, perceiving a higher intoxication level to be safe for taking the wheel was associated with a higher frequency of DACU (Borodovsky et al., 2020). Conversely, the likelihood of DACU is lower among those who believe that this behaviour increases the risk of accidents or other negative consequences (Davis et al., 2016). Deficits caused 
by the effects of cannabis are often perceived to be less important than those of alcohol (Fischer et al., 2006; Kelly, Darke, \& Ross, 2004). The perceptions that DACU is a lower risk behaviour than driving after using alcohol have been previously observed in scientific literature, although these studies present their inherent limitations (Roth, 2015). In addition, DACU may be related to the influence of peers. As such, being a passenger in a vehicle driven by a person under the influence of cannabis was associated with a future likelihood of that passenger engaging in DACU (Álvarez, Fierro, \& Del Río, 2007).

Although scientific interest in DACU has increased in recent years, most knowledge about individuals who engage in DACU comes from the USA (Berg et al., 2018). Additionally, Americans have significantly higher odds than Canadians to report DACU (adjusted odds ratio $[\mathrm{aOR}]=2.07 ; 95 \% \mathrm{CI}=1.66-2.57 ; \mathrm{p}<.001)$ and to declare being a passenger of another person who has engaged in DACU $(\mathrm{aOR}=1.49 ; 95 \% \mathrm{CI}=1.32-1.67 ; \mathrm{p}<.001)$, but they have lower odds of perceiving a risk of accidents related to DACU $(\mathrm{aOR}=0.70 ; 95 \% \mathrm{CI}=0.64-0.76 ; \mathrm{p}<.001)$ (Wadsworth \& Hammond, 2019). Data were often collected among specific groups such as adolescents who just learned how to drive or college/university students. Furthermore, most studies have focused on a few risk factors associated with DACU, but few proposed a more integrative model that would account for different types of characteristics. In other words, from previous findings, a model of DACU should include sociodemographic characteristics, variables associated with substance use and related problems, attitudes towards cannabis and DACU, risktaking (notably through other dangerous road behaviours) and peer influence. Considering that the proportion of alcohol-related road traffic fatalities has decreased significantly in recent years, notably because of public information campaigns (Christophersen, Mørland, Stewart, \& Gjerde, 2016), similar interventions may be relevant in the case of cannabis driving prevention. While 
universal prevention programmes are helping to keep the behaviour at a lower prevalence, some campaigns need to be more targeted towards those who are less likely to feel concerned by more general messaging. Considering limited resources allocated to DACU prevention, national policies need to be focused in order to have the largest impact. Building on previous findings, this study proposes an integrative risk factor model that will allow identifying the most contributive variables among known risk factors.

\section{METHODS}

\section{Study Population}

Participants were recruited via Facebook paid advertising between August 7, 2018, and March 7 , 2019. They needed to be between 17 and 35 years old, live in Canada, have used cannabis in the past 12 months and possess a regular or a probationary driver's licence. To possess a legal probationary driver's licence, an individual had to be at least 17 years old. The sample was restricted to young adults, considering that previous literature found they were the age that was most inclined to drive after using cannabis (Davis et al., 2016; Domingo-Salvany et al., 2017; Voas et al., 2013).

All questionnaires were self-administered online. The median duration for questionnaire completion was 21 minutes. A CA\$15 coupon for an online store was given after completion. Of the 3,796 individuals who accessed the survey's website, 2,270 participants gave their consent. Cases were excluded if they had entire missing datasets $(n=1,045)$ or if they were deemed careless respondents $(n=99)$. Careless respondents were participants who gave inconsistent or improbable answers throughout the questionnaires. Following data checking and cleaning, 1,126 participants were included in the final sample. This study was approved by the local institutional review board 
(approbation number DIS-1819-54). It was performed following the ethical standards outlined in the 1964 Declaration of Helsinki and its later amendments.

\section{Measures}

\section{Outcome Variable}

The outcome variable was measured by the following question: 'In the last 12 months, how many times did you drive within two hours after using cannabis?' Previous studies have used the twohour definition (Arterberry et al., 2013; Arterberry et al., 2017; Minaker et al., 2017; Wilson et al., 2018) and correspond to the time frame where THC blood level is at its peak, regardless of whether the person had smoked or ingested cannabis (Capler et al., 2017). Frequencies were dichotomized into 'no' (i.e. never) and 'yes' (i.e. once or more).

\section{Sociodemographic Variables}

Age was categorized as 17 to 25 years old and 26 to 35 years old. The cutoff at 25 was determined by the original definition of emerging adulthood by Arnett (2000) and by previous reports that 1824-year olds are the most open to the idea of engaging in DACU (Davis et al., 2016). Participants self-declared their sex assigned at birth (female, male and undetermined) and the gender to which they identify, that is, female, male, cultural gender (two-spirit, agowka, etc.) and other gender identities (gender-fluid, non-binary, etc.). Urbanity/rurality and province of residence were determined using the postal code. Participants could declare themselves as part- or full-time students, part- or full-time workers or having another type of occupation (unemployed, on disability leave, a stay-at-home parent, etc.). Education level attainment was dichotomized into 'high school diploma or less' and 'higher than high school diploma', considering that some 
participants were too young to have started university (for example, in Québec, first-year university students are generally 18-19 years old). Inspired by the Canada's First Poverty Reduction Strategy (Employment and Social Development Canada, 2018), the annual income before taxation was categorized as follows: less than CA $\$ 17,000 ; \mathrm{CA} \$ 17,000$ to $\mathrm{CA} \$ 29.999$; CA $\$ 30,000$ to $\mathrm{CA} \$ 69,999$; and $\mathrm{CA} \$ 70,000$ or more.

\section{Substance Use Variables}

Heavy drinking was set as five drinks or more for men and four drinks or more for women on the same occasion according to Canadian guidelines (Statistics Canada, 2019). Frequency of cannabis use over the past 12 months was assessed using an eight-point Likert scale. This variable has been recoded into three groups: occasionally, weekly or almost every week and daily or almost every day. Heavy use was considered as the use of three or more cannabis joints on the same occasion. For this specific variable, only smoking was assessed considering that it is the most common method of consumption in Canada (Health Canada, 2019, 2020). Cannabis-related problems were measured using the Cannabis Use Disorders Identification Test (CUDIT), a 10-item questionnaire that identifies individuals who meet the DSM criteria for cannabis use disorders (Adamson \& Sellman, 2003). This questionnaire is a modification of the Alcohol Use Disorders Identification Test (Saunders, Aasland, Babor, De La Fuente, \& Grant, 1993). The higher the score, the more likely the person presents problems related to cannabis use.

\section{Marijuana Effect Expectancies}

The Marijuana Effect Expectancies Questionnaire (MEEQ) measured to which extent one expects effects to occur as a result of using cannabis (Schafer \& Brown, 1991). This questionnaire was 
made up of six subscales. Cognitive and Behavioral Impairment referred to difficulties concentrating or understanding others, not being able to express oneself clearly and slow thinking and actions. Individuals who endorsed the Relaxation and Tension Reduction subscale expected cannabis to help them unwind, to make them less tense, to relieve their anxiety, to make them calm and to get a sense of relaxation. Social and Sexual Facilitation consisted of items related to increased talkativeness and sociability, as well as feeling more romantic or sexually attracted to others. Perceptual and Cognitive Enhancement was a subscale which encompassed increased creativity and imagination, different perception of music and better focus on one thing. Individuals who scored highly on Global Negative Effects expected to feel down, to lose control, to become careless or to be angry and possibly violent after using cannabis. Finally, the Craving and Physical Effects subscale referred to hunger and craving for snacks ('munchies') or other things.

\section{Driving Behaviour Variables}

A scale from 0 to 9 ('9 times or more') measured how often a participant drove within $1 \mathrm{~h}$ after drinking alcohol in the past 12 months. The perception that driving after using cannabis is unsafe was measured with a subscale of the Marijuana Driving Under Influence Behavior and Openness questionnaire (Davis et al., 2016), a five Likert-type ( 1 = 'totally disagree' and 5 = 'totally agree') items scale. Negative emotions while driving, aggressiveness and risky driving were assessed by the Dula Dangerous Driving Index (DDDI), a 29-item Likert-type (1 = 'never' and 5 = 'always') questionnaire (Dula \& Ballard, 2003). The Perceived Accessibility Scale assessed to what extent public transport was perceived as a convenient and hassle-free means of transportation. A score was generated by calculating the average of four Likert-type items $(1=$ 'totally agree' and $7=$ 'totally disagree'). 
Peer-Related Variables

A first peer-related variable was the number of friends who drive under the influence of cannabis. A second peer variable was the level of friends' approval of driving after cannabis use. Participants declared on a scale from 1 to 7 whether most of their friends would definitively disapprove of them (1) or definitely approve of them (7) from driving under the influence of cannabis. These peerrelated variables were derived from a questionnaire developed by members of our team and aimed at describing behaviours and perceptions related to driving after using any substance.

\section{Statistical Analyses}

All analyses were performed using IBM SPSS Statistics 25. Data checking allowed for skewness correction and recoding of outliers (over 3 SDs). Bivariate comparisons (Student T-tests for continuous variables and $\chi 2$ for categorical variables) were performed to detect significant differences between individuals who had driven within $2 \mathrm{~h}$ after using cannabis and those who did not take the wheel after cannabis use. Significant variables from bivariate analyses were then entered into a hierarchical logistic regression model. Model 1 included all the sociodemographic characteristics. Substance use related variables were added in Model 2. The five expected effects of cannabis were included in Model 3. Model 4 included variables related to driving behaviour. Finally, peer-related variables were entered in Model 5. Logistic regression statistical assumptions were checked and were met. 


\section{RESULTS}

The final sample consisted of 1,126 Canadian cannabis users with a valid driver's licence. The following sociodemographic characteristics differ from the ones found in the general population, considering that this study focused specifically on young adult drivers who use cannabis. Concerning gender identity, $48.8 \%$ declared to be female, $45.7 \%$ considered themselves male and $5.5 \%$ identified themselves as non-binary, gender-fluid, bispiritual or belonging to another gender identity. They were $25.8 \pm 5.3$ years old on average. Most participants were living in Ontario (31.8\%) and Québec (25.0\%). Fewer than half lived in an urban area (43.0\%). Work was the only main occupation for $63.7 \%, 19.1 \%$ were exclusively students, and $13.9 \%$ were both working and studying. The majority $(65.9 \%)$ had a college or university education. The majority (53.1\%) earned less than CA $\$ 30,999 /$ year; 35.8\%, between CA $\$ 30,000$ and CA $\$ 69,999$; and $11.1 \%$ had an income of CA $\$ 70,000$ or more. In the past 12 months, $55.7 \%$ of participants reported having driven within $2 \mathrm{~h}$ of using cannabis, for a mean number of 5.96 times ( $\mathrm{SD}=3.29)$.

Table 1 presents bivariate comparisons between individuals who had not driven after using cannabis in the past 12 months and those who had. In statistical terms, significantly more participants who engaged in DACU declare being male and reside in Québec, but were significantly less likely to be a student or to have low income. A higher proportion of individuals who engaged in DACU also report binge drinking frequently, using cannabis daily or almost daily, smoking three joints or more on one occasion, and having a higher CUDIT score for cannabisrelated problems. They also tend to have more positive expectations concerning cannabis (relaxation and tension reduction, social facilitation, and perceptual amplification) and fewer negative expectations regarding cognitive and behavioural disturbances. They report a higher 
number of drunk driving episodes and they presented higher scores in all subscales of dangerous driving as assessed by the DDDI.

Table 2 presents the hierarchical logistic regression model. Socio-demographic variables entered in the first step explained $9.7 \%$ of the variance. Being 17-25-years-old, male, a worker and belonging to a middle- or high-income class predicted driving after using cannabis. When variables related to substance use were added in the second step, the explained variance increased to $43.5 \%$. Working without simultaneously studying, earning CA $\$ 30,000$ or over, binge drinking, using cannabis weekly or daily, smoking three joints or more per occasion and having a higher CUDIT score predicted the behaviour. Expectations concerning cannabis use were then entered in the third step of the regression, which did not add much to the explained variance (47.0\%). Lower expectations concerning cognitive and behavioural disturbances and negative effects, but higher expectations concerning perceptual amplification were associated with driving after using cannabis. Belonging to middle or high classes, binge drinking, weekly-to-daily cannabis use, smoking three joints or more on the same occasion and higher CUDIT score remained significant predictors. The fourth step with variables concerning driving increased the explained variance to 68.2\%. Drunk driving in the past 12 months, believing that driving after using cannabis is safe, driving in a risky manner, using cannabis weekly or daily, having a higher CUDIT score and expecting that cannabis improves social interactions all predicted driving after using cannabis. Those who drove aggressively, who expected negative effects concerning cannabis use or who perceived satisfactory accessibility using public transportation were less likely to drive after cannabis use. The fifth and final model, which incorporates peer variables, slightly increased the explained variance to $69.0 \%$. Earning between $\mathrm{CA} \$ 30,000$ and $\mathrm{CA} \$ 69,000$, weekly to daily cannabis use, a higher CUDIT score, the expectation that cannabis facilitates social interactions, 
drunk driving, believing that driving after using cannabis is safe, risky driving behaviours, having a few friends who had DACU and thinking that friends will approve of DACU all predicted the behaviours. Conversely, older age (i.e. being 26-35-years-old), holding negative expectations concerning cannabis effects, driving aggressively and being more optimistic concerning accessibility using public transportation decreases the probability of driving after using cannabis.

\section{DISCUSSION}

Within the recent context of cannabis legalization in Canada, this study sought to identify the most prominent risk factors associated with DACU in order to inform efforts in developing more targeted prevention and intervention programmes that would help reduce this behaviour across the country. While previous studies have identified many relevant characteristics to tackle, most research was conducted mainly in the USA, among specific groups such as students, in relatively small samples, or limited to one city or region (i.e. state or province). Although Canada neighbours the USA, social, political and cultural differences may make it impossible to assume that findings obtained from American samples are entirely applicable to Canadian samples. With restricted financial and human resources, programmes need to be efficient by targeting Canadian young adults most inclined to engage in DACU by focussing on main risk factors.

When only sociodemographic characteristics were considered in Model 1, younger age, being male, being a worker (vs. being a student) and earning over CA $\$ 30,000$ per year were associated with an increased likelihood of engaging in DACU. However, as other blocks were entered into the regression model, these sociodemographic variables, except for age and income (CA $\$ 30,000-C A \$ 69,000$ vs. less than CA $\$ 17,000)$, were no longer significant predictors of DACU. Previous studies have not found significant associations between sociodemographics and 
DACU after controlling for other variables. There are many explanations why younger age remains associated with DACU after controlling for other variables related to substance use, driving behaviours and peer influence. Emerging adults younger than 25 are more prone to risk-taking and to be impulsive due to ongoing brain maturation (Taber-Thomas \& Pérez-Edgar, 2016). They also have more opportunities to use cannabis, which explains why the prevalence of cannabis use is the highest in this age group (Rotermann, 2019). They are more likely to present an optimism bias where 'bad things' happen to others, while 'good things' tend to occur for them (Arnett, 2014). Considering that the explained variance by sociodemographic characteristics is less than $10 \%$ and that their association with DACU may be explained by the presence of more relevant characteristics, prevention or intervention programmes should not be focused mainly on them.

Substance use variables are high contributors to predict DACU. Concerning heavy drinking frequency, this variable was initially associated with DACU; this result converges with some previous studies conducted mainly on young students (Arterberry et al., 2017; Minaker et al., 2017; Wilson et al., 2018). However, heavy drinking was no longer significantly associated with DACU when variables related to driving behaviours, such as the frequency of driving within $1 \mathrm{~h}$ after drinking any quantity of alcohol, were considered. This mirrors another study where heavy drinking, defined by drinking more than six drinks on one occasion, was not associated with DACU when other risky road behaviours were also considered in the regression model (Whitehill et al., 2019). Concerning the frequency of cannabis use, this study replicates previous findings. Even after including other variables in the model, weekly-to-daily cannabis use remains a strong predictor of DACU. However, heavy cannabis use frequency (three joints or more on the same occasion) became not significant when driving behaviours and peer variables models were added. Heavy use may be strongly associated with driving behaviours and peer variables, denoting a 
general tendency towards deviant behaviours. This result suggests also that frequent cannabis use, rather than heavy use, is more likely to predict the behaviour. Also, using a high quantity of cannabis on the same occasion may lead to such a high level of impairment, leading to the decision of not to engage in DACU. Otherwise, several studies come to similar conclusions (Cook et al., 2017; Le Strat et al., 2015; Scherer et al., 2013). Since problems related to cannabis use are correlated with the frequency of cannabis, it is not surprising that they are both strong predictors of DACU. While frequency of cannabis use and cannabis-related problems appear to be associated with DACU, our results do not allow inferring causality nor directionality. Intervention studies are eventually needed to determine if reducing the frequency of cannabis use or cannabis-related problems actually has an impact on lowering DACU behaviour. This study's findings rather suggest that prevention and intervention efforts should be geared towards adapting their messages to individuals who report high cannabis use frequency or with a cannabis use disorder.

Attitudes and expectations are relevant cognitive factors to consider in explaining DACU because they are modifiable through prevention and intervention strategies. Expected effects of cannabis use did not contribute substantially to the explained variance. Only two MEEQ subscales were significant predictors of DACU: social/sexual facilitation and expectations of negative effects. This latter variable was statistically non-significant in the bivariate analysis, but became significant in the multivariable regression model, probably due to a suppressor effect of another variable (Smith, Ager, \& Williams, 1992). According to one study conducted among college students, social/sexual facilitation did not predict whether someone engaged or not in DACU, but it was associated with increased DACU frequency among a subsample of drivers who took the wheel after using cannabis (Arterberry et al., 2013). Two other studies do not report that social/sexual facilitation, nor any positive effect expectancy, were associated with DACU among 
151 weekly-to-daily cannabis users in the community (Aston et al., 2016) or among 85 college students (King, Elder, \& Teeters, 2020). One possible explanation for our divergent result compared to previous studies may be attributed to the fact that our sample composition was more diverse and was more representative of the general population between 17 and 35 years old, not only college students or frequent users. Our results and partially those reported by Arterberry et al. (2013) suggest that individuals who expect that cannabis makes them more talkative and sociable may be more prone to use this substance in social gatherings. DACU is more likely to occur in this context, where one needs to drive back home after a social event, which is less the case if one is at home and using it for non-social purposes. Concerning the expectation of negative effects, three studies conducted among students found an association between this expectancy and engaging in DACU (Arterberry et al., 2013; Ewing et al., 2015; King et al., 2020). Individuals who expect that cannabis use will lead to a depressed state, a loss of control or feelings of anger and violence are less inclined to engage in DACU. It can be hypothesized that someone who has negative expectations of cannabis use may be less prone to use it, reducing, therefore, the likelihood of engaging in DACU. In short, expectations regarding cannabis use might be relevant but weak predictors of DACU. Considering that only a few studies have examined expectations in the context of DACU, further research is needed to confirm our results with a large representative sample.

Drunk driving frequency was associated with a higher likelihood of engaging in DACU, as found in a previous study (Arterberry et al., 2017). This suggests that, for some individuals, driving after alcohol or any other drug use is likely to occur regardless of the substance. Interestingly, heavy drinking no longer appears as a significant predictor when drunk driving is entered into the model. Considering that previous studies report that heavy alcohol use is related to drunk driving 
(Hingson, Zha, \& White, 2017; Minaker et al., 2017; Sloan, Eldred, \& Davis, 2014; Wilson et al., 2018), this suggests that it is not alcohol use in itself that explains DACU. However, believing that DACU is not a risky behaviour was a significant predictor in our model. Previous studies report that individuals who use cannabis frequently tend to consider that this substance does not impair their abilities to drive, or not as much as driving under the influence of alcohol, even claiming that cannabis improves it (Arterberry et al., 2013; Arterberry et al., 2017; Aston et al., 2016; Berg et al., 2018; Cavazos-Rehg et al., 2016; Davis et al., 2016; Greene, 2018; Matthews et al., 2014; Wickens et al., 2019). These drivers report compensatory driving behaviours while engaging in DACU such as driving more slowly (Greene, 2018; Wickens et al., 2019). However, slow driving will not systematically prevent a driver from making mistakes caused by slow reaction times, altered perception of time and distance or reduced concentration and attention span (Beirness \& Porath, 2019; Doroudgar et al., 2018). While focused attention may be perceived as heightening attention, cannabis actually reduces divided attention, which is crucial to avoid unexpected road events, for example, jaywalking pedestrians or animals inadvertently crossing the middle of the road (Bondallaz et al., 2016). Therefore, facts concerning the impacts of cannabis use on driving ability need to be presented credibly to frequent cannabis users or those who present a cannabis use disorder. One challenge for prevention will be to debunk a strong myth (i.e. that DACU is not a risky behaviour) that is currently promulgated by personal and anecdotal experiences. The fourth model also shows that aggressiveness while driving is inversely related to DACU. A previous study finds no association between DACU and aggressive driving, but reported that individuals who engage in DACU may experience aggressive feelings but will not act them out towards other drivers (Richer \& Bergeron, 2009). Furthermore, the self-perception of being less aggressive and 
more relaxed on the road may also contribute to their own belief that their driving is less impulsive and risky when they use cannabis.

Our results show that a higher score in risky driving is associated with DACU; this finding has been reported in previous studies (Bédard et al., 2007; Bergeron, Langlois, \& Cheang, 2014; Fergusson, Horwood, \& Boden, 2008). Given that DACU appears to be associated with impulsive road behaviours (e.g. drunk driving and risky driving), it is hypothesized that there is a common denominator among all these behaviours that will need to be identified and addressed in prevention and intervention strategies. In other words, the focus to address DACU should be on some personality traits of frequent users (e.g. sensation seeking, impulsivity and risk-taking, all of which are personal characteristics that underlie a 'general deviance syndrome' as posited by the Problem Behaviour Theory, Donovan \& Jessor, 2016; Jessor, 2016) rather than on the substance itself. This will hopefully also reduce the presence of other dangerous road behaviours. It is plausible that subtypes of DACU exist and would need to be identified to target better the subgroups of people adopting this behaviour. Typology studies are required and may reveal various profiles including some that are not related to risky behaviour tendency, such as chronic cannabis users who have 'no choice' but to engage in DACU because they need to drive to get around, or who have developed a high tolerance such that being under the influence of cannabis has become their usual state.

On another note, as expected and consistent with scientific literature, perceiving that accessibility of getting around is reduced when using public transportation increases the likelihood of engaging in DACU. This finding has been found for driving after drug use in general (Calafat et al., 2009; Degenhardt, Dillon, Duff, \& Ross, 2006; Neale, Mckeganey, Hay, \& Oliver, 2001). At first sight, one would suggest that improving the public transportation infrastructure may 
decrease the likelihood of driving after substance use. However, not all municipalities and regions may have the required material, human and financial resources to develop such efficient transportation services. Reducing the occurrence of DACU through better public transportation will also require changing habits and perceptions that one may hold towards public transit services. Otherwise, driving services such as the 'Operation Red Nose' programme during Christmas time (where drunk individuals give their keys to volunteers who will drive them back home) or Ubertype services could also help to decrease the rate of DACU. Reassuringly, these results suggest that prevention and intervention strategies that target road-related attitudes and behaviours may eventually have an impact on DACU. This assumption however needs to be confirmed in future research.

Participants who report that some of their friends are taking the wheel after cannabis use were more likely to do it themselves compared to those who reported that none of their friends do it. However, as the number of friends who engage in DACU increased, the result was no longer significant. This finding diverges from other studies which report that the likelihood of DACU increases proportionally to the number of friends who engage in DACU (Ewing et al., 2015; Kohn et al., 2014). Another study has not found any association between DACU and the number of friends who exhibit this same behaviour (Whitehill et al., 2019). Finally, the perception of peer approval of DACU increases significantly the probability of doing it. Two previous studies also report a similar finding (Aston et al., 2016; Ward, Schell, Kelley-Baker, Otto, \& Finley, 2018), while another does not find any association between injunctive norms and DACU (Arterberry et al., 2013). Considering a lack of scientific consensus concerning the role of peers and friends on DACU, further research is needed to determine if certain circumstances need to be present for this factor to have an effect. Particularly, future studies should aim to disentangle socialization and 
selection processes among young adults when studying peer variables as well as reciprocal friendships in order to understand friends and peers influences on DACU behaviours more accurately. Socialization versus selection has been examined mainly among adolescents but rarely among young adults (Becker \& Curry, 2014; Tucker, de la Haye, Kennedy, Green, \& Pollard, 2014).

Taken together, these different risk factors can be tied to different theories. According to French authors, risk-taking behaviours are more frequent in late adolescence and early adulthood because they represent modern versions of ritualistic trials and ordeals; young individuals need to confront potentially deadly situations so they can demonstrate control and mastery skills in order to enter fully into adulthood (Le Breton, 2001; Valleur, 2009). Additionally, individuals who engage in DACU also engage in other risky behaviours such as frequent or problematic substance use, speeding and drunk driving. Engaging in many different risky behaviours constitutes a 'general tendency of deviance', as explained by the Problem Behaviour Theory. Some individuals tend to deviate from desirable or conventional social norms as a result of different risk factors (models for engaging in risky behaviours, opportunities and contexts favourable for general deviance, personal psychological and biological vulnerabilities, etc.) that were not attenuated by protective factors such as positive models for pro-social behaviour, social controls and experiences of health-enhancing behaviours (Donovan \& Jessor, 2016; Jessor, 2016). This theory has been used to explain driving under the influence of alcohol and DACU among adolescents and young adults (Jessor, 1987; Shope \& Bingham, 2002). This general tendency towards risky behaviours may be partly explained by lower cortisol reactivity to stress as it has been associated with increased risk-taking and greater sensation seeking and criminal tendencies (Cima, Smeets, \& Jelicic, 2008; Daughters, Gorka, Matusiewicz, \& Anderson, 2013; Freeman \& Beer, 2010). This 
biomarker was found to be more prevalent among individuals with elevated generalized risky driving behaviours (Brown et al., 2020), including those who drive while impaired (Couture et al., 2015). Furthermore, according to the Theory of Planned Behaviour, a behaviour is driven by personal attitudes, subjective norms and perceived behavioural control (Ajzen, 1985; 1987). As such, our results show that individuals who engage in DACU held more positive attitudes towards cannabis and DACU (a belief that DACU is safe, higher expectations that cannabis facilitates social interactions, lower expectations that cannabis brings negative effects), are more likely to perceive friends' approval of DACU (subjective injunctive norms), and perceive reduced accessibility (i.e. possibility to get around) and control when using public transportation, that is, difficulty in using it (behavioural control). Finally, Social Learning Theories (Akers, 2013; Bandura and Walters, 1977) suggest that the different reported risk factors for DACU were mainly learned and shaped by their social environment, especially through peers' attitudes and actions that were considered models to follow. However, our data do not allow inference whether peer selection or socialization occurred. While these different theories help interpret our reported results, the findings of this present study do not allow us to confirm nor invalidate them.

\section{Limits}

This study presents some limitations. Firstly, data were self-reported. Participants may have minimized or exaggerated their answers or were more reluctant to reveal sensitive information, especially in the context where DACU is a federal criminal offence. However, previous studies show that self-reported criminal behaviours and substance use (especially tobacco and cannabis) constituted valid data, with moderate to strong correlation coefficients with official records (Johnston \& O’Malley, 1985; Thornberry \& Krohn, 2003). Impact of social desirability is 
considerably reduced when using computerized versions of questionnaires and when respondents are anonymous (Richman, Kiesler, Weisband, \& Drasgow, 1999). In this study, online anonymity and explicit mention of terms of confidentiality should have reduced this specific bias. Self-report data were chosen over administrative data and roadside surveys, considering that many assessed factors in this study relied on personal experiences that cannot be observed by an external entity. Also, recruitment and misclassification biases can occur when using administrative data (e.g. individuals suspected of risky driving by police officers, etc.) or roadside surveys (e.g. individuals who generally engage in DACU but were not doing so at the exact time of roadblock, etc.). Moreover, memory bias may have occurred, considering that some questions referred to events that happened in the past 12 months. On a related note, a single type of informant (i.e. young drivers reporting about themselves) provided the data, which cannot be cross-checked with other sources. However, if the individual always engages in DACU unbeknownst to either family members or friends, and was never arrested, that person remains the only possible informant of the behaviour. Secondly, the cross-sectional design of this study does not allow to infer causality between independent variables and DACU. It is noteworthy to mention that longitudinal designs do not overcome this limitation in disentangling the directionality of associations. However, these predictors may be helpful in shaping prevention and intervention programmes aimed at DACU. Thirdly, the inclusion criteria restricted the sample to young adults with a legal probationary or regular driver's licence. Our results may not be generalized to all cannabis users. Fourthly, selfselection bias may have occurred considering that analyses were conducted in a convenience sample of individuals who were motivated to fill out a 20-minute questionnaire and who had Internet access. Finally, our definition of DACU captures all individuals who have used any quantity of cannabis, without any possible inference to intoxication level. This type of assessment 
is open to other types of bias, as the experience of 'feeling high' is subjective and may vary from one use to another.

\section{CONCLUSION}

This study highlights the importance of addressing DACU to reduce potential risks of accidents and deaths, considering that more than half of Canadian cannabis users have taken the wheel after using cannabis in the past 12 months. One of the strongest predictors were frequent cannabis use and higher levels of cannabis use disorders or related problems. Therefore, not all cannabis users are inclined to engage in DACU as they do not constitute a heterogeneous population. This result also implies that individuals who are frequent users or who present cannabis-related problems should be part of the development of targeted prevention programmes against DACU. Better detection of drivers with cannabis-related problems is recommended to offer appropriate services. Their inclusion into focus groups or other qualitative research designs will allow for a more nuanced understanding of their inner motivations for this behaviour and to what kind of prevention messages they would be most sensitive. Beyond prevention, their implication in studies using a participative approach will help complement and intensify current interventions to ensure that the services meet more of their needs more accordingly. Without their participation in development prevention or intervention programmes, any message aimed towards them will not be heard, be perceived as credible or be accepted by them (Stevens et al., 2019). 


\section{Acknowledgements}

The authors would like to thank Valérie Aubut, Ervane Kamgang, Paul Macalli and Ian MacPhail for their technical support during recruitment and data collection. They also thank Philip Dawkins for the linguistic revision. This research was made possible with the financial contribution of the Canadian Institutes of Health Research (\#SHI-155642). 


\section{REFERENCES}

Adamson, S. J., Sellman, J. D. (2003). A prototype screening instrument for cannabis use disorder: The cannabis use disorders identification test (CUDIT) in an alcoholdependent clinical sample. Drug and Alcohol Review, 22(3), 309-315. https://doi.org/10.1080/0959523031000154454.

Ajzen, I. (1985). From intentions to actions: A theory of planned behavior. In: Kuhl, J., Beckmann, J. (Éds.), Action control: From cognition to behavior (p. 11-39). New York, NY: Springer. https://doi.org/10.1007/978-3-642-69746-3_2.

Ajzen, I. (1987). Attitudes, traits, and actions: Dispositional prediction of behavior in personality and social psychology. In: Berkowitz, L. (Éd.), Advances in experimental social psychology (Vol. 20, p. 1-63). Cambridge, USA: Academic Press. https://doi.org/10.1016/S0065-2601(08)60411-6.

Akers, R. L (2013). Criminological theories: Introduction and evaluation. Oxfordshire, UK: Routledge.

Álvarez, F. J., Fierro, I., Del Río, M. C. (2007). Cannabis and driving: Results from a general population survey. Forensic Science International, 170(2), 111-116. https://doi.org/10.1016/j.forsciint.2007.03.024.

Arnett, J. J. (2000). Emerging adulthood: A theory of development from the late teens through the twenties. American Psychologist, 55(5), 469-480.

Arnett, J. J. (2014). Emerging adulthood: The winding road from the late teens through the twenties. Oxford, UK: Oxford University Press. 
Arterberry, B. J., Treloar, H., McCarthy, D. M. (2017). Empirical profiles of alcohol and marijuana use, drugged driving, and risk perceptions. Journal of Studies on Alcohol and Drugs, 78(6), 889-898. https://doi.org/10.15288/jsad.2017.78.889.

Arterberry, B. J., Treloar, H. R., Smith, A. E., Martens, M. P., Pedersen, S. L., McCarthy, D. M. (2013). Marijuana use, driving, and related cognitions. Psychology of Addictive Behaviors: Journal of the Society of Psychologists in Addictive Behaviors, 27(3), 854860. https://doi.org/10.1037/a0030877.

Asbridge, M., Hayden, J. A., Cartwright, J. L. (2012). Acute cannabis consumption and motor vehicle collision risk: Systematic review of observational studies and meta-analysis. BMJ: British Medical Journal, 15, 344. https://doi.org/10.1136/bmj.e536.

Aston, E. R., Merrill, J. E., McCarthy, D. M., Metrik, J. (2016). Risk factors for driving after and during marijuana use. Journal of Studies on Alcohol and Drugs, 77(2), 309-316. https://doi.org/10.15288/jsad.2016.77.309.

Bandura, A., Walters, R. H. (1977). Social learning theory (Vol. 1). Englewood Cliffs, NJ: Prentice Hall.

Becker, S. J., Curry, J. F. (2014). Testing the effects of peer socialization versus selection on alcohol and marijuana use among treated adolescents. Substance Use and Misuse, 49(3), 234-242. https://doi.org/10.3109/10826084.2013.824479.

Bédard, M., Dubois, S., Weaver, B. (2007). The impact of cannabis on driving. Canadian Journal of Public Health, 98(1), 6-11. https://doi.org/10.1007/BF03405376.

Beirness, D. J., Porath, A. J. (2019). Clearing the smoke on cannabis: Cannabis use and drivingan update (p. 7). Ottawa, ON: Canadian Centre on Substance Use and Addiction. 
https://www.ccsa.ca/sites/default/files/2019-10/CCSA-Cannabis-Use-Driving-Report2019-en_1.pdf.

Berg, C. J., Daniel, C. N., Vu, M., Li, J., Martin, K., Le, L. (2018). Marijuana use and driving under the influence among young adults: A socioecological perspective on risk factors. Substance Use and Misuse, 53(3), 370-380. https://doi.org/10.1080/10826084.2017.1327979.

Bergeron, J., Langlois, J., Cheang, H. S. (2014). An examination of the relationships between cannabis use, driving under the influence of cannabis and risk-taking on the road. European Review of Applied Psychology, 64(3), 101-109. https://doi.org/10.1016/j.erap.2014.04.001.

Bergeron, J., Paquette, M. (2014). Relationships between frequency of driving under the influence of cannabis, self-reported reckless driving and risk-taking behavior observed in a driving simulator. Journal of Safety Research, 49, 19-24. https://doi.org/10.1016/j.jsr.2014.02.002.

Bingham, C. R., Shope, J. T., Zhu, J. (2008). Substance-involved driving: Predicting driving after using alcohol, marijuana, and other drugs. Traffic Injury Prevention, 9(6), 515526. https://doi.org/10.1080/15389580802273698.

Bondallaz, P., Favrat, B., Chtioui, H., Fornari, E., Maeder, P., Giroud, C. (2016). Cannabis and its effects on driving skills. Forensic Science International, 268, 92-102. https://doi.org/10.1016/j.forsciint.2016.09.007.

Borodovsky, J. T., Marsch, L. A., Scherer, E. A., Grucza, R. A., Hasin, D. S., Budney, A. J. (2020). Perceived safety of cannabis intoxication predicts frequency of driving while 
intoxicated. Preventive Medicine, 131, 105956.

https://doi.org/10.1016/j.ypmed.2019.105956.

Brown, T. G., Ouimet, M. C., Nadeau, L., Tremblay, J., Gianoulakis, C., Couture, S., MoxleyKelly, N. (2020). Cortisol stress response predicts 9-year risky driving convictions in male first-time driving-while-impaired offenders. Psychopharmacology, 237(1), 177187. https://doi.org/10.1007/s00213-019-05359-0.

Calafat, A., Blay, N., Juan, M., Adrover, D., Bellis, M. A., Hughes, K., Bohrn, K. (2009). Traffic risk behaviors at nightlife: Drinking, taking drugs, driving, and use of public transport by young people. Traffic Injury Prevention, 10(2), 162-169. https://doi.org/10.1080/15389580802597054.

Capler, R., Bilsker, D., Van Pelt, K., MacPherson, D. (2017). Cannabis use and driving: Evidence review (pp. 1-66). Canadian Drug Policy Coalition. https://drugpolicy.ca/wpcontent/uploads/2017/02/CDPC_Cannabis-and-Driving_EvidenceReview_FINALV2_March27-2017.pdf.

Cavazos-Rehg, PA, Housten, AJ, Krauss, MJ, Sowles, SJ, Spitznagel, EL, Chaloupka, FJ, Bierut, LJ (2016). Selected state policies and associations with alcohol use behaviors and risky driving behaviors among youth: Findings from monitoring the future study. Alcoholism, Clinical and Experimental Research, 40(5), 1030-1036. https://doi.org/10.1111/acer.13041.

Choi, N. G., DiNitto, D. M., Marti, C. N. (2019). Older adults driving under the influence: Associations with marijuana use, marijuana use disorder, and risk perceptions. Journal of Applied Gerontology, 38(12), 1687-1707. https://doi.org/10.1177/0733464817745379. 
Christophersen, A. S., Mørland, J., Stewart, K., Gjerde, H. (2016). International trends in alcohol and drug use among vehicle drivers. Forensic Science Review, 28(1), 37-66.

Cima, M., Smeets, T., Jelicic, M. (2008). Self-reported trauma, cortisol levels, and aggression in psychopathic and non-psychopathic prison inmates. Biological Psychology, 78(1), 7586. https://doi.org/10.1016/j.biopsycho.2007.12.011.

Cook, S., Shank, D., Bruno, T., Turner, N. E., Mann, R. E. (2017). Self-reported driving under the influence of alcohol and cannabis among Ontario students: Associations with graduated licensing, risk taking, and substance abuse. Traffic Injury Prevention, 18(5), 449-455. https://doi.org/10.1080/15389588.2016.1149169.

Couture, S, Ouimet, MC, Gianoulakis, C, Tremblay, J, Ng Ying Kin, N, Brochu, S, Brown, TG (2015). Lower cortisol activity is associated with first-time driving while impaired. Substance Abuse: Research and Treatment, 9, 25-32. https://doi.org/10.4137/SART.S21353.

Cuttler, C., Sexton, M., Mischley, L. K. (2018). Driving under the influence of cannabis: An examination of driving beliefs and practices of medical and recreational cannabis users across the United States. Cannabis, 1(2), 1-13. http://dx.doi.org/10.26828/cannabis.2018.02.001.

Danton, K., Misselke, L., Bacon, R., Done, J. (2003). Attitudes of young people toward driving after smoking cannabis or after drinking alcohol. Health Education Journal, 62(1), 5060. https://doi.org/10.1177/001789690306200106.

Daughters, S. B., Gorka, S. M., Matusiewicz, A., Anderson, K. (2013). Gender specific effect of psychological stress and cortisol reactivity on adolescent risk taking. Journal of 
Abnormal Child Psychology, 41(5), 749-758. https://doi.org/10.1007/s10802-013-97134.

Davis, K. C., Allen, J., Duke, J., Nonnemaker, J., Bradfield, B., Farrelly, M. C., Shafer, P., Novak, S. (2016). Correlates of marijuana drugged driving and openness to driving while high: Evidence from Colorado and Washington. PloS One, 11(1), e0146853. https://doi.org/10.1371/journal.pone.0146853.

Degenhardt, L., Dillon, P., Duff, C., Ross, J. (2006). Driving, drug use behaviour and risk perceptions of nightclub attendees in Victoria, Australia. International Journal of Drug Policy, 17(1), 41-46. https://doi.org/10.1016/j.drugpo.2005.12.004.

Domingo-Salvany, A., Herrero, M. J., Fernandez, B., Perez, J., del Real, P., González-Luque, J. C., de la Torre, R. (2017). Prevalence of psychoactive substances, alcohol and illicit drugs, in Spanish drivers: A roadside study in 2015. Forensic Science International, 278, 253-259. https://doi.org/10.1016/j.forsciint.2017.07.005.

Donovan, J. E., Jessor, R. (2016). Problem Behavior Theory and the Problem Behavior Syndrome. In: The origins and development of problem behavior theory. Advancing responsible adolescent development. Basel, Switzerland: Springer, Cham.

Doroudgar, S., Mae Chuang, H., Bohnert, K., Canedo, J., Burrowes, S., Perry, P. J. (2018). Effects of chronic marijuana use on driving performance. Traffic Injury Prevention, 19(7), 680-686. https://doi.org/10.1080/15389588.2018.1501800.

Duff, C., Rowland, B. (2006). 'Rushing behind the wheel': Investigating the prevalence of 'drug driving' among club and rave patrons in Melbourne, Australia. Drugs: Education, Prevention and Policy, 13(4), 299-312. https://doi.org/10.1080/09687630600625946. 
Dula, C. S., Ballard, M. E. (2003). Development and evaluation of a measure of dangerous, aggressive, negative emotional, and risky driving. Journal of Applied Social Psychology, 33(2), 263-282. https://doi.org/10.1111/j.1559-1816.2003.tb01896.x .

Employment and Social Development Canada (2018). Opportunity for all-Canada's first poverty reduction Strategy (pp. 1-105). Government of Canada. https://www .canada.ca/en/employment-social-development/programs/povertyreduction/reports/strategy.html.

Ewing, B. A., Tucker, J. S., Miles, J. N. V., Shih, R. A., Kulesza, M., Pedersen, E. R., D’Amico, E. J. (2015). Early substance use and subsequent DUI in adolescents. Pediatrics, 136(5), 868-875. https://doi.org/10.1542/peds.2015-1143.

Fergusson, D. M., Horwood, L. J., Boden, J. M. (2008). Is driving under the influence of cannabis becoming a greater risk to driver safety than drink driving? Findings from a longitudinal study. Accident Analysis and Prevention, 40(4), 1345-1350. https://doi.org/10.1016/j.aap.2008.02.005.

Fischer, B., Rodopoulos, J., Rehm, J., Ivsins, A. (2006). Toking and driving: characteristics of Canadian university students who drive after cannabis use - an exploratory pilot study. Drugs: Education, Prevention and Policy, 13(2), 179-187. https://doi.org/10.1080/09687630500512335.

Freeman, H. D., Beer, J. S. (2010). Frontal lobe activation mediates the relation between sensation seeking and cortisol increases. Journal of Personality, 78(5), 1497-1528. https://doi.org/10.1111/j.1467-6494.2010.00659.x. 
Greene, K. M. (2018). Perceptions of driving after marijuana use compared to alcohol use among rural American young adults. Drug and Alcohol Review, 37(5), 637-644. https://doi.org/10.1111/dar.12686.

Hartman, R. L., Huestis, M. A. (2013). Cannabis effects on driving skills. Clinical Chemistry, 59(3), 478-492. https://doi.org/10.1373/clinchem.2012.194381.

Health Canada (2019). Canadian cannabis survey 2019-summary. https://www.canada.ca/en/health-canada/services/publications/drugs-healthproducts/canadian-cannabis-survey-2019-summary.html.

Health Canada (2020). Canadian cannabis survey 2020-summary. https://www.canada.ca/en/health-canada/services/drugs-medication/cannabis/researchdata/canadian-cannabis-survey-2020-summary.html.

Hingson, R. W., Zha, W., White, A. M. (2017). Drinking beyond the binge threshold: Predictors, consequences, and changes in the U.S. American Journal of Preventive Medicine, 52(6), 717-727. https://doi.org/10.1016/j.amepre.2017.02.014.

Jessor, R. (1987). Risky driving and adolescent problem behavior: An extension of problembehavior theory. Alcohol, Drugs and Driving, 3(3-4), 1-11.

Jessor, R. (2016). Problem Behavior Theory over the Years. The origins and development of problem behavior theory. Advancing responsible adolescent development. Springer, Cham.

Johnston, L. D., O’Malley, P. M. (1985). Issues of validity and population coverage in student surveys of drug use. In Rowe, B. A., Kozel, N. J., Richards, L. G. (Eds.), Self-report methods of estimating drug use: Meeting current challenges to validity (NIDA research monograph No. 57 (pp. 31-54). Rockville, MD: National Institute on Drug Abuse. 
Kelly, E., Darke, S., Ross, J. (2004). A review of drug use and driving: Epidemiology, impairment, risk factors and risk perceptions. Drug and Alcohol Review, 23(3), 319344. https://doi.org/10.1080/09595230412331289482.

King, S., Elder, S., Teeters, J. (2020). Negative cannabis expectancies are associated with drinking after cannabis use. Cannabis, 3(2), 173-179. https://doi.org/10.26828/cannabis.2020.02.004.

Kohn, C., Saleheen, H., Borrup, K., Rogers, S., Lapidus, G. (2014). Correlates of drug use and driving among undergraduate college students. Traffic Injury Prevention, 15(2), 119124. https://doi.org/10.1080/15389588.2013.803221.

Le Breton, D. (2001). Les conduites à risque des jeunes. In Penser les pratiques sociales (pp. 4956). Érès. https://doi.org/10.3917/eres.puyue.2001.01.0049.

Le Strat, Y., Dubertret, C., Le Foll, B. (2015). Impact of age at onset of cannabis use on cannabis dependence and driving under the influence in the United States. Accident Analysis and Prevention, 76, 1-5. https://doi.org/10.1016/j.aap.2014.12.015.

Matthews, A. J., Bruno, R., Dietze, P., Butler, K., Burns, L. (2014). Driving under the influence among frequent ecstasy consumers in Australia: Trends over time and the role of risk perceptions. Drug and Alcohol Dependence, 144, 218-224. https://doi.org/10.1016/j.drugalcdep.2014.09.015.

Mikulskaya, E., Martin, F. (2018a). Visual attention to motion stimuli and its neural correlates in cannabis users. European Journal of Neuroscience, 47(3), 269-276. https://doi.org/10.1111/ejn.13810. 
Mikulskaya, E., Martin, F. H. (2018b). Contrast sensitivity and motion discrimination in cannabis users. Psychopharmacology, 235(8), 2459-2469. https://doi.org/10.1007/s00213-018-4944-2.

Minaker, L. M., Bonham, A., Elton-Marshall, T., Leos-Toro, C., Wild, T. C., Hammond, D. (2017). Under the influence: Examination of prevalence and correlates of alcohol and marijuana consumption in relation to youth driving and passenger behaviours in Canada. A cross-sectional study. CMAJ Open, 5(2), E386-E394. https://doi.org/10.9778/cmajo.20160168.

Neale, J., Mckeganey, N., Hay, G., Oliver, J. (2001). Recreational drug use and driving: A qualitative study. (No 00988494; p. 1-86). Scottish Executive Central Research Unit. https://trid.trb.org/view/753985.

O’Malley, P. M., Johnston, L. D. (2013). Driving after drug or alcohol use by US high school seniors, 2001-2011. American Journal of Public Health, 103(11), 2027-2034. https://doi.org/10.2105/AJPH.2013.301246.

Richer, I., Bergeron, J. (2009). Driving under the influence of cannabis: Links with dangerous driving, psychological predictors, and accident involvement. Accident Analysis and Prevention, 41(2), 299-307. https://doi.org/10.1016/j.aap.2008.12.004.

Richman, W. L., Kiesler, S., Weisband, S., Drasgow, F. (1999). A meta-analytic study of social desirability distortion in computer-administered questionnaires, traditional questionnaires, and interviews. Journal of Applied Psychology, 84(5), 754-775. https://doi.org/10.1037/0021-9010.84.5.754.

Rogeberg, O., Elvik, R. (2016). The effects of cannabis intoxication on motor vehicle collision revisited and revised. Addiction, 111(8), 1348-1359. https://doi.org/10.1111/add.13347. 
Rotermann, M. (2019). Analysis of trends in the prevalence of cannabis use and related metrics in Canada. Health Reports, 30(6), 3-13. https:/www150.statcan.gc.ca/n1/en/pub/82003-x/2019006/article/00001-eng.pdf?st=MKU4D0sv.

Roth, A. L. (2015). The uneasy case for marijuana as chemical impairment under a sciencebased jurisprudence of dangerousness (SSRN Scholarly Paper ID 2564646). 27961222. Social Science Research Network. https://papers.ssrn.com/abstract=2564646.

Saunders, J. B., Aasland, O. G., Babor, T. F., De La Fuente, J. R., Grant, M. (1993). Development of the alcohol use disorders identification test (AUDIT): WHO collaborative project on early detection of persons with harmful alcohol consumption-II. Addiction, 88(6), 791-804. https://doi.org/10.1111/j.1360-0443.1993.tb02093.x.

Schafer, J., Brown, S. A. (1991). Marijuana and cocaine effect expectancies and drug use patterns. Journal of Consulting and Clinical Psychology, 59(4), 558-565. https://doi.org/10.1037//0022-006x.59.4.558.

Scherer, M., Voas, R. B., Furr-Holden, D. (2013). Marijuana as a predictor of concurrent substance use among motor vehicle operators. Journal of Psychoactive Drugs, 45(3), 211-217. https://doi.org/10.1080/02791072.2013.804230.

Shope, J. T., Bingham, C. R. (2002). Drinking-driving as a component of problem driving and problem behavior in young adults. Journal of Studies on Alcohol, 63(1), 24-33.

Sloan, F. A., Eldred, L. M., Davis, D. V. (2014). Addiction, drinking behavior, and driving under the influence. Substance Use and Misuse, 49(6), 661-676. https://doi.org/10.3109/10826084.2013.858167.

Smith, R. L., Ager, J. W., Williams, D. L. (1992). Suppressor variables in multiple regression/correlation. Educational and Psychological Measurement, 52(1), 17-29. 
Statistics Canada (2019). Heavy drinking, 2018 (No 82-625-X; health fact sheets (pp. 1-6).

Government of Canada. https://www150.statcan.gc.ca/n1/pub/82-625x/2019001/article/00007-eng.htm.

Stevens, E. M., Cohn, A. M., Villanti, A. C., Leshner, G., Wedel, A., Wagener, T. L. (2019). Perceived effectiveness of anti-marijuana messages in adult users and nonusers: An examination of responses to messages about marijuana's effects on cognitive performance, driving, and health. Journal of Studies on Alcohol and Drugs, 80(4), 415422. https://doi.org/10.15288/jsad.2019.80.415.

Sukhawathanakul, P., Thompson, K., Brubacher, J., Leadbeater, B. (2019). Marijuana trajectories and associations with driving risk behaviors in Canadian youth. Traffic Injury Prevention, 20(5), 472-477. https://doi.org/10.1080/15389588.2019.1622097.

Taber-Thomas, B., Pérez-Edgar, K. (2016). Emerging adulthood brain development. In: Dans the Oxford handbook of emerging adulthood (pp. 126-141). Oxford, UK: Oxford University Press.

Terry, P., Wright, K. A. (2005). Self-reported driving behaviour and attitudes towards driving under the influence of cannabis among three different user groups in England. Addictive Behaviors, 30(3), 619-626. https://doi.org/10.1016/j.addbeh.2004.08.007.

Thornberry, T. P., Krohn, M. D. (2003). Comparison of self-report and official data for measuring crime. In: Measurement problems in Criminal justice research. Washington, DC: The National Academies Press. https://doi.org/10.17226/10581.

Tucker, J. S., de la Haye, K., Kennedy, D. P., Green, H. D., Pollard, M. S. (2014). Peer influence on marijuana use in different types of friendships. The Journal of Adolescent Health: 
Official Publication of the Society for Adolescent Medicine, 54(1), 67-73.

https://doi.org/10.1016/j.jadohealth.2013.07.025.

Valleur, M. (2009). Les chemins de l'ordalie. Topique, 107(2), 47-64.

https://doi.org/10.3917/top.107.0047.

Voas, R. B., Lacey, J. H., Jones, K., Scherer, M., Compton, R. (2013). Drinking drivers and drug use on weekend nights in the United States. Drug and Alcohol Dependence, 130, 215221. https://doi.org/10.1016/j.drugalcdep.2012.11.007.

Wadsworth, E., Hammond, D. (2019). International differences in patterns of cannabis use among youth: Prevalence, perceptions of harm, and driving under the influence in Canada, England and United States. Addictive Behaviors, 90, 171-175. https://doi.org/10.1016/j.addbeh.2018.10.050.

Ward, N. J., Schell, W., Kelley-Baker, T., Otto, J., Finley, K. (2018). Developing a theoretical foundation to change road user behavior and improve traffic safety: Driving under the influence of cannabis (DUIC). Traffic Injury Prevention, 19(4), 358-363. https://doi.org/10.1080/15389588.2018.1425548.

Wettlaufer, A., Florica, R. O., Asbridge, M., Beirness, D., Brubacher, J., Callaghan, R., Rehm, J. (2017). Estimating the harms and costs of cannabis-attributable collisions in the Canadian provinces. Drug and Alcohol Dependence, 173, 185-190. https://doi.org/10.1016/j.drugalcdep.2016.12.024.

Whitehill, J. M., Rodriguez-Monguio, R., Doucette, M., Flom, E. (2019). Driving and riding under the influence of recent marijuana use: Risk factors among a racially diverse sample of young adults. Journal of Ethnicity in Substance Abuse, 18(4), 594-612. https://doi.org/10.1080/15332640.2018.1425951. 
Wickens, C. M., Watson, T. M., Mann, R. E., Brands, B. (2019). Exploring perceptions among people who drive after cannabis use: Collision risk, comparative optimism and normative influence. Drug and Alcohol Review, 38(4), 443-451. https://doi.org/10.1111/dar.12923.

Wilson, M. N., Cumming, T., Burkhalter, R., Langille, D. B., Ogilvie, R., Asbridge, M. (2018). Driving under the influence behaviours among high school students who mix alcohol with energy drinks. Preventive Medicine, 111, 402-409. https://doi.org/10.1016/j.ypmed.2017.11.035. 
Table 1. Descriptive and comparative analyses

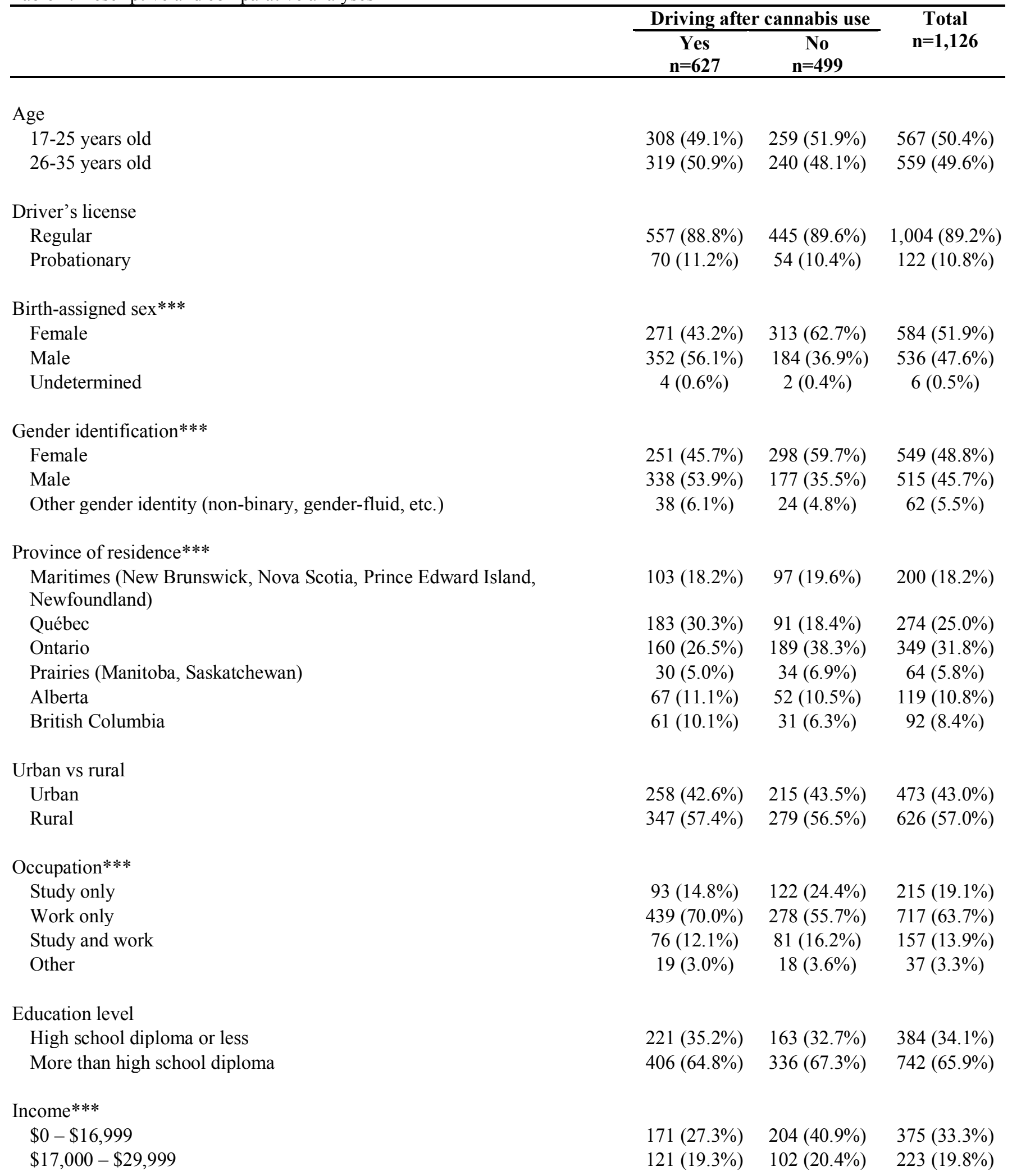


$\$ 30,000-\$ 69,999$
$\$ 70,000$ and over

Heavy drinking frequency***

Never

Once

Twice

3-5 times

6 times or more

Cannabis use frequency (past 12 months) ***

Daily or almost daily use

Weekly use

Occasional use

Heavy cannabis use frequency (past 12 months)***

Cannabis effect expectancies

Cognitive and behavioural disturbances***

Relaxation and tension reduction***

Social facilitation*

Perceptual amplification***

Negative effects

Craving and physical symptoms

Cannabis related problems (CUDIT total score)***

Dangerous driving

Negative emotions***

Aggressiveness***

Risky driving***

Drunk driving frequency***

DACU frequency***

Belief that driving after using cannabis is safe $* * *$

Perceived accessibility of public transportation***

Number of friends that drive after cannabis use $* * *$

None

Some of them

Many of them

All or almost all of them

Peer approval of driving after cannabis use $* * *$

$$
\begin{array}{ccc}
241(38.4 \%) & 162(32.5 \%) & 403(35.8 \%) \\
94(15.0 \%) & 31(6.2 \%) & 125(11.1 \%)
\end{array}
$$

$\begin{array}{ccc}180(28.7 \%) & 200(40.1 \%) & 380(33.7 \%) \\ 141(22.5 \%) & 137(27.5 \%) & 278(24.7 \%) \\ 111(17.7 \%) & 75(15.0 \%) & 186(16.5 \%) \\ 130(20.7 \%) & 70(14.0 \%) & 200(17.8 \%) \\ 65(10.4 \%) & 17(3.4 \%) & 82(7.4 \%)\end{array}$

$391(62.4 \%) \quad 134(26.9 \%)$

$219(34.9 \%) \quad 213(42.7 \%)$

$17(2.7 \%) \quad 152(30.5 \%)$

$525(46.6 \%)$

$432(38.4 \%)$

$169(15.0 \%)$

$0.97 \pm 0.87 \quad 0.28 \pm 0.50 \quad 0.66 \pm 0.80$

$\begin{array}{lll}2.49 \pm 1.09 & 3.07 \pm 1.04 & 2.74 \pm 1.11 \\ 4.17 \pm 0.84 & 3.85 \pm 0.96 & 4.03 \pm 0.91 \\ 3.07 \pm 0.84 & 2.94 \pm 0.89 & 3.01 \pm 0.86 \\ 3.52 \pm 0.87 & 3.04 \pm 0.96 & 3.31 \pm 0.94 \\ 1.78 \pm 0.94 & 1.83 \pm 0.85 & 1.80 \pm 0.90 \\ 3.59 \pm 0.93 & 3.64 \pm 0.95 & 3.61 \pm 0.94 \\ & & \\ 12.00 \pm 7.42 & 5.25 \pm 4.85 & 9.01 \pm 7.23\end{array}$

$21.09 \pm 6.99$

$19.2 \pm 6.41$

$20.27 \pm 6.80$

$13.33 \pm 6.02$

$11.40 \pm 4.78$

$12.48 \pm 5.59$

$24.95 \pm 9.69$

$17.82 \pm 6.19$

$21.79 \pm 9.04$

$0.67 \pm 0.93$

$0.15 \pm 0.45$

$0.44 \pm 0.80$

$5.95 \pm 3.29$

-

$3.31 \pm 3.84$

$3.64 \pm 0.97$

$2.09 \pm 0.91$

$2.96 \pm 1.22$

$2.95 \pm 1.58$

$3.49 \pm 1.80$

$3.19 \pm 1.70$

$36(5.7 \%)$

$308(49.1 \%)$

$161(32.3 \%)$

$197(17.5 \%)$

$152(24.2 \%)$

$260(52.1 \%)$

568 (50.4\%)

$131(20.9 \%)$

$47(23.6 \%)$

$199(17.7 \%)$

$162(14.4 \%)$

$4.37 \pm 1.68 \quad 2.40 \pm 1.63 \quad 3.50 \pm 1.93$

$* \mathrm{p}<.05 ; * * \mathrm{p}<.01 ; * \mathrm{p}<.001$ 
Table 2. Hierarchical logistic regression model

\begin{tabular}{|c|c|c|c|c|c|}
\hline & $\begin{array}{c}\text { Model } 1 \\
\text { OR }[95 \% \mathrm{CI}]\end{array}$ & $\begin{array}{c}\text { Model } 2 \\
\text { OR }[95 \% \mathrm{CI}]\end{array}$ & $\begin{array}{c}\text { Model } 3 \\
\text { OR }[95 \% \mathrm{CI}]\end{array}$ & $\begin{array}{c}\text { Model } 4 \\
\text { OR [95\%CI] }\end{array}$ & $\begin{array}{c}\text { Model } 5 \\
\text { OR }[95 \% \mathrm{CI}]\end{array}$ \\
\hline \multicolumn{6}{|l|}{ Sociodemographic variables } \\
\hline Age (ref : $17-25$ years old) & $\begin{array}{c}0.682 \\
{[0.5094-0.913]^{*}}\end{array}$ & $\begin{array}{c}0.802 \\
{[0.571-1.126]}\end{array}$ & $\begin{array}{c}0.762 \\
{[0.538-1.081]}\end{array}$ & $\begin{array}{c}0.638 \\
{[0.412-0.987]^{*}}\end{array}$ & $\begin{array}{c}0.607 \\
{[0.390-0.943]^{*}}\end{array}$ \\
\hline \multicolumn{6}{|l|}{ Gender identity (ref : female) } \\
\hline Male & $\begin{array}{c}1.973 \\
{[1.525-2.552] * * *}\end{array}$ & $\begin{array}{c}1.336 \\
{[0.979-1.824]}\end{array}$ & $\begin{array}{c}1.296 \\
{[0.933-1.799]}\end{array}$ & $\begin{array}{c}0.764 \\
{[0.504-1.157]}\end{array}$ & $\begin{array}{c}0.771 \\
{[0.507-1.173]}\end{array}$ \\
\hline Bispirit, gender-fluid, non-binary or other & $\begin{array}{c}1.703 \\
{[0.994-2.948]}\end{array}$ & $\begin{array}{c}0.993 \\
{[.536-1.840]}\end{array}$ & $\begin{array}{c}1.022 \\
{[0.540-1.935]}\end{array}$ & $\begin{array}{c}0.813 \\
{[0.366-1.805]}\end{array}$ & $\begin{array}{c}0.858 \\
{[0.377-1.951]}\end{array}$ \\
\hline \multicolumn{6}{|l|}{ Occupation (ref: study only) } \\
\hline Work only & $\begin{array}{c}1.630 \\
{[1.120-2.371]^{*}}\end{array}$ & $\begin{array}{c}1.584 \\
{[1.012-2.478]^{*}}\end{array}$ & $\begin{array}{c}1.496 \\
{[0.944-2.371]}\end{array}$ & $\begin{array}{c}1.155 \\
{[0.648-2.059]}\end{array}$ & $\begin{array}{c}1.170 \\
{[0.653-2.094]}\end{array}$ \\
\hline Work and study & $\begin{array}{c}1.172 \\
{[0.763-1.799]}\end{array}$ & $\begin{array}{c}1.657 \\
{[0.977-2.808]}\end{array}$ & $\begin{array}{c}1.485 \\
{[0.862-2.558]}\end{array}$ & $\begin{array}{c}1.370 \\
{[0.715-2.625]}\end{array}$ & $\begin{array}{c}1.456 \\
{[0.751-2.825]}\end{array}$ \\
\hline Other & $\begin{array}{c}1.751 \\
{[0.839-3.656]}\end{array}$ & $\begin{array}{c}2.287 \\
{[0.933-5.606]}\end{array}$ & $\begin{array}{c}1.748 \\
{[0.700-4.366]}\end{array}$ & $\begin{array}{c}1.131 \\
{[0.371-3.447]}\end{array}$ & $\begin{array}{c}1.260 \\
{[0.402-3.954]}\end{array}$ \\
\hline \multicolumn{6}{|l|}{ Income (ref: less than $\$ 17,000$ ) } \\
\hline$\$ 17,000-\$ 29,000$ & $\begin{array}{c}1.293 \\
{[0.902-1.854]}\end{array}$ & $\begin{array}{c}1.196 \\
{[0.780-1.835]}\end{array}$ & $\begin{array}{c}1.262 \\
{[0.812-1.963]}\end{array}$ & $\begin{array}{c}1.019 \\
{[0.588-1.767]}\end{array}$ & $\begin{array}{c}1.072 \\
{[0.614-1.873]}\end{array}$ \\
\hline$\$ 30,000-\$ 69,000$ & $\begin{array}{c}1.661 \\
{[1.173-2.350]^{*}}\end{array}$ & $\begin{array}{c}1.797 \\
{[1.189-2.718]^{* * *}}\end{array}$ & $\begin{array}{c}1.823 \\
{[1.190-2.793]^{* *}}\end{array}$ & $\begin{array}{c}1.615 \\
{[0.950-2.746]}\end{array}$ & $\begin{array}{c}1.729 \\
{[1.006-2.970]^{*}}\end{array}$ \\
\hline$\$ 70,000$ and over & $\begin{array}{c}3.129 \\
{[1.840-5.323]^{* * *}}\end{array}$ & $\begin{array}{c}2.088 \\
{[1.101-3.962]^{*}}\end{array}$ & $\begin{array}{c}2.307 \\
{[1.195-4.454]^{*}}\end{array}$ & $\begin{array}{c}1.629 \\
{[0.711-3.735]}\end{array}$ & $\begin{array}{c}1.740 \\
{[0.746-4.058]}\end{array}$ \\
\hline $\begin{array}{l}\text { Education level } \\
\text { (ref: more than high school) }\end{array}$ & $\begin{array}{c}1.228 \\
{[0.984-1.614]}\end{array}$ & $\begin{array}{c}0.952 \\
{[0.687-1.318]}\end{array}$ & $\begin{array}{c}0.962 \\
{[0.687-1.345]}\end{array}$ & $\begin{array}{c}0.723 \\
{[0.478-1.093]}\end{array}$ & $\begin{array}{c}0.711 \\
{[0.467-1.081]}\end{array}$ \\
\hline \multicolumn{6}{|l|}{ Substance use variables } \\
\hline Heavy drinking & & $\begin{array}{c}1.399 \\
{[1.015-1.929]^{*}}\end{array}$ & $\begin{array}{c}1.463 \\
{[1.049-2.042]^{*}}\end{array}$ & $\begin{array}{c}1.292 \\
{[0.854-1.956]}\end{array}$ & $\begin{array}{c}1.255 \\
{[0.822-1.916]}\end{array}$ \\
\hline \multicolumn{6}{|l|}{$\begin{array}{l}\text { Cannabis use frequency } \\
\text { (ref: occasional use) }\end{array}$} \\
\hline Weekly use & & $\begin{array}{c}4.504 \\
{[2.556-7.938]^{* * *}}\end{array}$ & $\begin{array}{c}3.512 \\
{[1.950-6.327]^{* * *}}\end{array}$ & $\begin{array}{c}3.503 \\
{[1.725-7.116]^{* *}}\end{array}$ & $\begin{array}{c}3.338 \\
{[1.638-6.802]^{* *}}\end{array}$ \\
\hline Daily use & & $\begin{array}{c}7.268 \\
{[3.958-13.348] * * *}\end{array}$ & $\begin{array}{c}4.320 \\
{[2.231-8.366]^{* * *}}\end{array}$ & $\begin{array}{c}4.869 \\
{[2.161-10.969] * * *}\end{array}$ & $\begin{array}{c}4.562 \\
{[2.008-10.363]^{* * *}}\end{array}$ \\
\hline $\begin{array}{l}\text { Heavy cannabis use frequency } \\
\text { ( } 3 \text { joints or more) }\end{array}$ & & $\begin{array}{c}1.870 \\
{[1.456-2.401]^{* * *}}\end{array}$ & $\begin{array}{c}1.649 \\
{[1.267-2.147] * * *}\end{array}$ & $\begin{array}{c}1.224 \\
{[0.892-1.680]}\end{array}$ & $\begin{array}{c}1.188 \\
{[0.859-1.643]}\end{array}$ \\
\hline Cannabis use problems (CUDIT score) & & $\begin{array}{c}1.110 \\
{[1.077-1.144] * * *}\end{array}$ & $\begin{array}{c}1.140 \\
{[1.102-1.179] * * *}\end{array}$ & $\begin{array}{c}1.096 \\
{[1.052-1.143]^{* * * *}}\end{array}$ & $\begin{array}{c}1.097 \\
{[1.051-1.145]^{* * *}}\end{array}$ \\
\hline
\end{tabular}




\section{Cannabis effect expectancies}

Cognitive and behavioural disturbances

0.767

$[0.649-0.906]^{* *}$

0.942

Relaxation and tension reduction

Social facilitation

Perceptual amplification

Negative effects

Craving and physical symptoms

\section{Driving behaviours variables}

Drunk driving frequency

Belief that driving after using cannabis is safe

\section{Dangerous driving}

Negative emotions

Aggressiveness

Risky driving

Perceived accessibility of public transportation

\section{Peer variables}

Number of friends that drive after cannabis use (ref: none)

Some of them

\section{Many of them}

All or almost all of them

Peer approval of driving after cannabis use

Nagelkerke's $\mathrm{R}^{2}$

Hosmer and Lemshow's test
$[0.751-1.132]$ 1.100

1.2818

$[1.075-1.545]$ ** 0.733

[0.583 - 0.920$]$ *

0.870

[0.729 - 1.038]
[0.915 - 1.323]
1.177

$[0.948-1.461]$

1.118

[0.850 - 1.472]

1.438

$[1.150-1.797]$ * *

1.092

[0.871 - 1.368]

0.544

$[0.401-.738] * * *$

0.819

[0.658 - 1.018]

2.816

$[1.979-4.008] * * *$

3.474

$[2.776-4.347] * * *$

1.005

[0.959 - 1.053]

0.924

[0.862 - 0.989]*

1.083

$[1.034-1.135]^{* *}$

0.797

$[0.708-0.896]^{* * *}$
1.173

[0.943 - 1.460] 1.092

[0.827 - 1.443]

1.4506

[1.196 - 1.897]**

1.105

[0.880 - 1.387]

0.553

$[0.407-0.753]^{* * *}$ 0.831

[0.666 - 1.036]

2.615

$[1.833-3.731] * * *$ 3.076

$[2.412-3.731] * * *$

1.001

[0.955 - 1.050]

0.921

[0.860 - 0.988]*

1.081

$[1.032-1.133] * *$

0.783

$[0.702-0.895]^{* * *}$

1.846

$[1.053-3.237] *$

1.906

[0.908-4.004] 1.052

[0.441 - 2.510]

1.154

[1.001 - 1.330]*

$69.0 \%$

$\mathrm{X}^{2}=12,325 ; \mathrm{p}=.137$

$$
* \mathrm{p}<.05 ; * * \mathrm{p}<.01 ; * \mathrm{p}<.001
$$

